\title{
Jan Frohloff
}

\section{Verletzung von Schiedsvereinbarungen}

Eine Untersuchung des deutschen Schiedsverfahrensrechts zu den Pflichten der Schiedsparteien und den Rechtsfolgen ihrer Verletzung

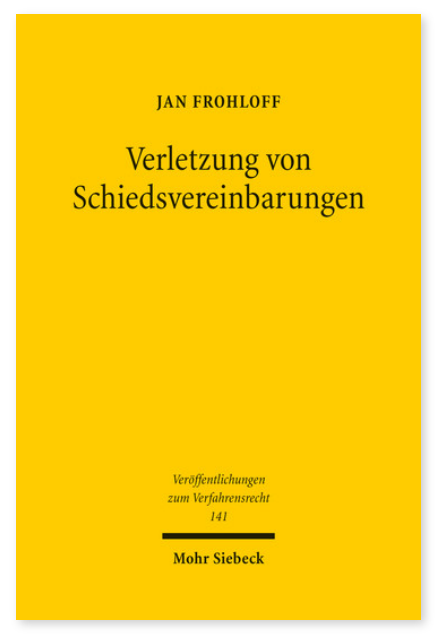

2017. XXII, 285 Seiten. VVerfR 141

ISBN 978-3-16-155383-7

DOI 10.1628/978-3-16-155383-7

eBook PDF $89,00 €$

ISBN 978-3-16-155382-0

fadengeheftete Broschur $89,00 €$
Schiedsvereinbarungen haben im heutigen Wirtschaftsverkehr eine große Bedeutung. Doch welche Pflichten entstehen aus der Schiedsvereinbarung und welche Rechtsfolgen hat eine Pflichtverletzung? Jan Frohloff legt mit seiner Arbeit die erste umfassende Untersuchung zu diesem Thema für das deutsche Schiedsverfahrensrecht vor. Er differenziert zwischen schiedsvertraglichen Pflichten und Lasten und leitet fünf Pflichten ab, die für die Parteien einer Schiedsvereinbarung entstehen. Für diese fünf schiedsvertraglichen Pflichten stellt der Autor dar, ob eine Pflichtverletzung einen Anspruch auf Schadensersatz auslöst, ob die Pflichten vor einem staatlichen Gericht oder einem Schiedsgericht durchgesetzt werden können und ob sich eine Schiedspartei bei einer Pflichtverletzung der Gegenseite von der Schiedsvereinbarung lösen kann.

„Das Werk ist ein Muss für alle am Schiedsverfahrensrecht Interessierten.«

Evgenia Peiffer RabelsZ 85 (2021), S. 711-715

»Frohloffs Arbeit gelingt es, eine Fülle praktisch relevanter Fragen auf ihr gemeinsames Fundament herunterzubrechen und auch komplexe Probleme gut verständlich zu beleuchten. Dabei belohnt er den Leser nicht nur mit einem umfassenden Überblick über den Stand von Rechtsprechung und Wissenschaft, sondern auch mit einem äußerst angenehmen Leseerlebnis, das jedem empfohlen werden kann, der sich für den theoretischen Unterbau des Schiedsverfahrensrechts interessiert."

Tobias A. Strecker SchiedsVZ 2022, S. 289-291

Jan Frohloff Geboren 1986; Studium der Rechtswissenschaften an der Johannes Gutenberg-Universität Mainz und am King's College London; Promotion mit Forschungsaufenthalten an der NYU School of Law und am Max-Planck-Institut für ausländisches und internationales Privatrecht in Hamburg; Rechtsreferendariat im Bezirk des Kammergerichts; Rechtsanwalt in Berlin im Bereich Prozessführung und Schiedsverfahren, insbesondere in Weltraumstreitigkeiten.

Jetzt bestellen:

https://mohrsiebeck.com/buch/verletzung-von-schiedsvereinbarungen-9783161553837?no_cache=1 order@mohrsiebeck.com

Telefon: +49 (0)7071-923-17

Telefax: +49(0)7071-51104 